\title{
Entrando en la segunda etapa de la democratización*
}

\begin{abstract}
Alain Touraine**
Estamos acostumbrados a debates políticos del mismo tipo que las discusiones entre miembros de la misma profesión, es decir, a debates unidimensionales -económicos, nacionales, religiosos, morales, etc.- que se parecen a un partido de tenis o a un combate de boxeo.

Pero los debates actuales y la política en general han cambiado del todo: son multidimensionales. Es fácil mencionar varias de estas dimensiones: siempre existen conflictos de intereses, pero más y más a menudo mezclados con enfrentamientos simbólicos. Todos, incluso los más locales, tienen una dimensión internacional. Finalmente, sabemos que la comunicación es tan importante como el contenido mismo del debate.

En términos más limitados y concretos: los debates actuales imponen a todos los campos imaginar la combinación de metas diferentes u opuestas. El defensor de intereses sociales tiene que encontrar argumentos propiamente económicos a favor de sus tesis, pero también tal vez argumentos feministas o de defensa de una minoría, y debe saber evitar las palabras y las imágenes que dan miedo o que quitan el coraje de tomar riesgos. El debate se desarrolla en el mismo momento en el parlamento, en mítines organizados por partidos, en programas de televisión que son escuchados en los bares o en los comedores. El papel de los expertos va disminuyendo porque los conocimientos precisos y complejos no se comunican fácilmente. Estos debates son aún más difíciles de entender por un público general que reacciona y toma decisiones no solamente como respuestas a una situación presente, sino también como resultado de su pasado personal y colectivo, de la influencia de algunos opinion makers y de la experiencia de otros países.

Los esfuerzos dedicados a defender una estrategia o la importancia de una meta tienen en la gran mayoría de los casos efectos negativos. Finalmente, y eso es lo más importante cuando se trata de temas sociales y políticos, el éxito de una acción colectiva depende de su capacidad de tener de manera simultánea dos significados aparentemente contradictorios: por un lado, convencer de la importancia y de la centralidad de un conflicto; por el otro, mostrar que la defensa de ciertos intereses corresponde también al bien común, al interés de todos.
\end{abstract}

\footnotetext{
* Este artículo constituye una de las colaboraciones de Alain Touraine en el marco del Seminario Internacional del Doctorado en Ciencias Sociales de la Universidad de Chile. Ello fue posible gracias a la invitación al profesor Touraine hecha por el Museo de la Memoria y los Derechos Humanos, con el apoyo de la Embajada de Francia, en septiembre de 2013.

** École de Hautes Études en Sciences Sociales.
} 
En un mundo globalizado un proyecto político en Chile debe ser compatible con la lógica industrial y comercial de un mundo fuertemente integrado, pero debe también defender la especificidad de los intereses nacionales, en particular del empleo.

Chile tiene vínculos fuertes con Estados Unidos y Europa, pero igualmente con China. En su historia reciente la imagen de Chile está a la vez dominada por Allende y por su adversario Pinochet y por largos esfuerzos de autolimitación de los cambios. De la misma manera es conocido por medio de imágenes con cargas simbólicas de extrema izquierda, y al mismo tiempo ha mantenido en los problemas de la sexualidad, de la familia, del divorcio o del aborto, valores directamente inspirados por la Iglesia Católica, lo que me convence de que la meta más importante para los políticos chilenos a todos los niveles es la integración de una gran variedad de proyectos y la búsqueda de un eje central en el campo definido de manera amplia.

¿Cuál puede o debe ser la meta central de los debates políticos en Chile? Elaborar y llevar a cabo un concepto de democracia que permita la integración más amplia posible de todos los proyectos específicos que corresponden a los varios sectores de la vida colectiva.

La derecha no puede proponer una solución autoritaria que provocaría un conflicto general en la sociedad. Siguiendo su tradición dominante, la derecha en Chile, como en otros países, recomienda confiar en la racionalidad del mercado y tiene desconfianza en las políticas recargadas de ideología. Pero este principio hace difícil para los dirigentes políticos defender los principios enseñados y defendidos por la Iglesia Católica. La importancia del comercio internacional en la economía chilena contribuye a dar, en las ideas de la derecha chilena actual, prioridad al liberalismo económico sobre el autoritarismo político. La presidencia actual ha manifestado su respeto en general del Estado de derecho.

En cuanto a la política, la respuesta que se me impone es la misma, pero en términos voluntaristas y no de obediencia al mercado. El debate político central es: ¿cuál es el principio más importante de orientación del sistema político? La derecha responde: el sistema de los mercados mundializados. La izquierda responde: el respeto de todos los derechos universales de los seres humanos, es decir, de los derechos que todos y todas poseen y que les dan la capacidad de actuar como sujetos, como actores libres reconocidos como portadores de derechos fundamentales.

No se trata aquí de defender un individualismo directo y completo que otorgue a cada uno o una el derecho de cumplir todos sus deseos, de llevar a cabo todos sus proyectos, de defender todos sus intereses, fórmula en realidad muy peligrosa en contradicción con el universalismo de los derechos.

La democracia no lucha solamente contra la dominación de los mercados; tiene también que rechazar hoy el evolucionismo de las filosofías de la historia y del progreso. No tenemos más la religión del progreso y del porvenir. Al contrario, somos más y más ambivalentes -tema muy bien renovado por las sociólogas italianas Simoneta Tabboni y María Calabró, pero que tiene raíces profundas en Simmel, Merton y Elias, en particular-. 
No podemos más identificar una política con el movimiento natural de la historia o con la supuesta racionalidad de los mercados financieros. ¿Por qué esta importancia central reconocida a los derechos humanos fundamentales, comunes a todos los seres humanos? Porque el siglo XX ha entregado un poder predominante a muchos agentes de los procesos de modernización, que tienden a identificar sus intereses de dirigentes con la misma modernidad, que es definida por el universalismo, tanto de la razón como de los derechos humanos fundamentales, lo que fue la utopía desastrosa del occidente hegemónico. El triunfo a partir de mediados de los años 70 del neoliberalismo que quiere dar un poder absoluto a los mercados resultó en gran parte de la incapacidad de las izquierdas, en casi todos los países del mundo, de desvincularse de las filosofías de la historia desarrolladas en el siglo XIX y de reconocer el papel central de los derechos humanos en la vida social y política.

A partir de la crisis de los subprimes en 2007, los gobiernos se preocuparon por evitar una nueva gran crisis semejante a la de 1929. Ayudaron, antes que todo en los Estados Unidos, a grandes empresas, y aún más después de la caída del banco Lehman Brothers el 15 de septiembre del 2008, a los bancos y a las grandes compañías de seguros. Los europeos, incluso los ingleses, hicieron lo mismo, y países como Italia llegaron a un nivel insoportable de endeudamiento público, en un país sin crecimiento durante el último decenio y condenado por los mercados financieros a pagar spreads muy elevados, de hasta $6 \%$, para conseguir prestamos indispensables para pagar los intereses de la deuda pública.

Esta política tuvo como consecuencia la incapacidad de algunos países, como Grecia, de pagar su deuda, y la necesidad difícilmente aceptada por los países europeos de una ayuda directa a algunos países. En realidad el sistema europeo llegó muy cerca del default y fue salvado solamente por la intervención muy atrevida del presidente del Banco Central Europeo, el italiano Mario Draghi. El año 2012-2013 fue el peor de toda la historia de la construcción europea.

Pero lo que nos preocupa aún más aquí es la incapacidad de todos los países de elaborar una política para superar la crisis. El único país que ha cambiado de perspectiva, buscando un camino diferente, es el Reino Unido, que dando la espalda a la Unión Europea, de la cual fue siempre un miembro lleno de dudas, ha decidido dar la prioridad al sistema financiero mundial, incluso en la protección de los paraísos fiscales, volviendo a crear un nuevo tipo de imperio británico.

El caso alemán es muy diferente. La fuerza de su industria hizo imposible para ella el abandono de su propia industria que decidió Inglaterra y, con los mismos resultados negativos pero un nivel más alto de inconsciencia, Francia, ahora menos industrializada que Italia. Ya conocemos la situación de España. Los países latinoamericanos dentro del efecto poderoso de las compras importantes de commodities de parte de China y de otros países, han seguido caminos diferentes: progreso fuerte de México ahora incorporado a América del Norte; lucha eficiente del Brasil de Lula durante su segunda presidencia contra su triste título de país más desigual del mundo; permanencia del espíritu peronista en Argentina, felizmente fortalecido por las compras chinas. 
La situación de Chile resumida en pocas palabras puede ser definida como un gran éxito económico gracias a sus exportaciones en gran parte tradicionales y a una política económica inteligente, prudente y competente. La presidencia derechista del presidente Piñera no ha introducido cambios mayores. De tal manera que me parece adecuado decir, sin ningún espíritu polémico, que Chile, en su conjunto, está preparado para entrar en un período de reformas sociales profundas para superar un nivel de desigualdades, y de casi segregación social -incluso étnica-, que puede crear en un futuro más o menos próximo el peligro real de una crisis a la vez social y política. En realidad pocos países tienen la misma capacidad económica y administrativa de Chile para superar sus problemas y para entrar rápidamente en el mundo que llamamos desarrollado, cuando sus recursos económicos, su Estado activo y abierto a las exigencias de la justicia social, y sus actores sociales convencidos de la necesidad de actuar dentro del marco democrático, combinan sus efectos positivos.

Los países de Europa occidental entre 1945 y 1975 (con excepción parcial de España que fue transformada políticamente solo después de la muerte de Franco en 1975 por Suárez y aún más por Felipe González) alcanzaron a transformarse en welfare states, o como dicen los alemanes en "economías sociales de mercado" (sozialmarktwirtschaft), y resistieron hasta el decenio de los 90 a la desorganización y a la irracionalidad económica de la especulación financiera antes de caer en la crisis.

Estos países encuentran inmensas dificultades para reinventar sus Estados de bienestar. Chile, al contrario, tiene delante de sí un camino casi abierto. Está incorporado en la economía mundial, abierto al Oriente tanto como al Occidente.

Ahora tengo que formular mi hipótesis positiva: Chile ha sufrido tanto en su carne humana y en sus instituciones y ha sido tan prudente, tan autolimitado en su política económica y en su proceso de redemocratización, que debe existir hoy en el espíritu y en el corazón de la gran mayoría de los chilenos la certitud de que lo que es justo hoy es a la vez posible y necesario. El pueblo chileno lo dirá muy luego y espero que lo diga con fuerza. Por razones distintas o incluso opuestas la gran mayoría de los chilenos puede darse cuenta de que es ahora que conviene cantar: ya viene la alegría.

Permítanme por un breve momento volver al mundo occidental para que ustedes se den cuenta de que la situación de Chile y de algunos otros países en el mundo es más favorable que la de muchos países occidentales para que se transformen rápidamente en países realmente desarrollados, categoría que me parece mucho más sólida que la de países emergentes, atribuida a los BRIC.

Es cierto que el triunfo del capitalismo financiero sobre el industrial ha producido consecuencias económicas negativas, en particular el aumento de la desocupación, pero no ha provocado crisis políticas insuperables. Con la excepción parcial de Italia, donde ha nacido el movimiento político "Cinque Stelle" dirigido por el cómico Pepe Grillo, que, con un fuerte apoyo electoral que viene tanto de la extrema derecha como de la extrema izquierda, Ilegó rápidamente a paralizar políticamente Italia, pero sin que el sistema político 
sea directamente amenazado. En total, Italia ha mostrado su capacidad de resistir a la crisis. En varios países europeos el "Movimiento de los Indignados" ha tenido efectos sociales y políticos importantes como consecuencia de la crisis económica, pero de la misma manera sin desencadenar una crisis política abierta.

En realidad, esta breve descripción de la situación occidental muestra al contrario la capacidad muy débil de iniciativa política de las izquierdas. Las redes de comunicación de los jóvenes educados, convocados por Facebook o Twitter, no resultan en movimientos permanentes o en cambios políticos profundos.

Aunque esta interpretación sea muy poco grata para mí, la hipótesis más racional es que la ausencia de crecimiento en Europa inmovilizó lo que muchos llaman el ascensor social. Los jóvenes educados con estudios universitarios o técnicos de nivel alto, simplemente porque son mucho más numerosos que antes, deben aceptar puestos de trabajo y niveles de ingreso inferiores a los que esperaban. En España, más de la mitad de los jóvenes no tienen empleo y la frustración es intensa. Pero este tipo de descontento, muy difícil de soportar para todos los individuos, no se transforma fácilmente en formas de acción colectiva.

De la misma manera nos llamó la atención, durante la reciente campaña presidencial de Obama en los Estados Unidos, que el escenario político de este país fue ocupado casi enteramente por la extrema derecha del Tea Party y, de manera más concreta, que el nivel de vida de los african-american, de los black, a pesar de la presencia de un presidente black, haya bajado (lo que se ha observado también en África del Sur a pesar de la eliminación del apartheid gracias a Mandela). El mundo occidental, después de la derrota de Hitler y de la desaparición de la Unión Soviética, quedó dominado por las redes financieras y las redes de comunicación que transmiten a la vez mass culture y mensajes interindividuales, más que ideas y debates que forman la opinión pública.

Estas primeras observaciones me llevan a formular tres hipótesis que tal vez se transformarán en conclusiones.

La primera es que en el período actual las políticas están dirigidas por intereses o por identidades nacionales, lingüísticas, religiosas, de género (sexuales), mientras los elementos universalistas que definen la modernidad pierden terreno en muchas partes. En los Estados Unidos y en Europa disminuye el número de estudiantes que se dedican a las ciencias fundamentales o al pensamiento social filosófico o artístico.

La segunda es que será más probablemente en los nuevos países modernizadores, en particular en los numerosos países que están dominados por regímenes autoritarios, que la falta de pensamiento y de acción universalistas serán sentidas y combatidas con más fuerza, mientras la experiencia histórica y personal de los viejos países occidentales, incluso del Japón, ha sido poco y mal reinterpretada en términos universalistas.

La tercera hipótesis es que el interés para el pensamiento y la acción universalistas se forma con más dificultades, se encuentra con más obstáculos, en los países en los cuales existen fuertes barreras sociales internas o una fuerte heterogeneidad étnica o religiosa. 
Antes de seguir este tipo de análisis, paremos un momento para explicar y justificar mi definición de la modernidad por el universalismo del pensamiento y de la acción. Es suficiente aquí mencionar tres componentes fundamentales de la modernidad:

El primero es el pensamiento racional, científico y técnico, lo que es fácil aceptar en nuestra época que conoce una creatividad científica y tecnológica sin precedentes. Sin dejar de ser breve quiero mencionar aquí la oposición de tan grande trascendencia entre la ecología política que aumenta el control y la protección del medio ambiente para permitir a los seres humanos y a muchos más sobrevivir en un medio altamente técnico y, por otro lado, la ideología de la desmodernización y de la desindustrialización inaugurada por el Club de Roma y que ha ganado terreno en ciertos países, especialmente en los Estados Unidos, en Canadá, en Gran Bretaña y en Alemania.

Sin hacer más comentarios quiero indicar, con toda claridad, que el primer tipo de ecología que defiende un sustainable growth es una parte indispensable de la modernidad, mientras el ecologismo antimoderno abre la puerta a crisis más y más profundas y peligrosas en un mundo en el cual sabemos que muchos países, entre ellos los más poderosos, están decididos a seguir creciendo para asegurar más recursos a sus habitantes y a sus dirigentes.

El segundo es la gran creación de la cultura occidental gracias a los pensadores griegos, cristianos, de la llustración y de muchas formas del individualismo y de la defensa de los derechos contemporáneos. La Revolución Francesa en 1789 le dio su expresión más famosa: Libertad, Igualdad y Fraternidad, en la Declaración de los Derechos de los Hombres y de los Ciudadanos.

El tercer elemento al cual otorgo una importancia central es el movimiento de simpatía; los antiguos griegos decían Philia y nuestros contemporáneos le llaman el corazón, o care, basado en el reconocimiento de que todos los seres humanos tienen una dignidad común independiente de cualquier atributo social, cultural o biológico.

A estas alturas creo que puedo hablar de manera directa: después de un siglo XX dominado por todas las formas de lucha y de liberación contra la hegemonía occidental y después contra las más poderosas fuerzas antidemocráticas como todas las dictaduras, la prioridad hoy para el mundo entero, y de manera muy especial para los países emergentes de los cuales Chile es un ejemplo conspicuo, es de volver a dar una prioridad central al universalismo en el pensamiento y la acción mediante el respeto a la razón y a los derechos de todos y todas y a la dignidad de cada ser humano. Es fácil formular estos tres puntos de manera más concreta:

1. El elemento más básico de la democracia, como bien lo dijo Norberto Bobbio, es la igualdad que debe ser a la vez igualdad de las oportunidades e igualdad de los estatutos. Una sociedad dividida en niveles muy desiguales es tan ajena a la democracia como una sociedad sin movilidad, sin posibilidad de cambiar de nivel.

2. El componente más amplio y diversificado de una sociedad que respeta el universalismo es la libertad; prefiero decir aquí el respeto de los derechos políticos, sociales y culturales, 
agregando de inmediato que todos los derechos reconocidos deben tener un contenido, un valor universalista.

3. En el siglo XVIII se hablaba mucho del amor de los hombres o de la humanidad. Hoy no se puede hablar más así, pero la idea expresada por medio de esta fórmula sigue teniendo sentido. Es fundamental tomar en serio la igualdad de los seres humanos, la unidad de la especie humana.

Uno de los horrores más espantosos del siglo XX fue el racismo. Hoy en muchas partes del mundo racismo, discriminación, segregación, son fuerzas poderosas, como se ve tanto en Europa como en el Medio Oriente o en la India, lo que el antropólogo Dumont, en un libro famoso, ha llamado el homo hierarchicus, pensando en primer lugar en la sociedad de castas de la India, lo opuesto del homo aequalis, que es universalista y define la modernidad. No hay programa político positivo que no luche activamente y con pasión contra todas las formas de racismo. No hay programa democrático en Chile que no considere como una meta de mayor importancia eliminar las discriminaciones de las cuales los mapuches son víctimas, tanto al sur del Biobío como en el gran Santiago o en otras ciudades.

No me atrevo a formular un programa económico o jurídico para un Chile que está muy bien encaminado en el respeto de los derechos fundamentales, pero veo, es obvio para mí como para mucha gente, que un proyecto político democrático no tiene sentido, no tiene ni siquiera realidad si no se compromete a disminuir fuertemente las desigualdades y a rechazar cualquier tipo de racismo y de discriminación social, cultural o religiosa.

Quiero poner un énfasis especial en dos temas que me parece ocupan un puesto central en el mundo actual.

En primer lugar frente a las desigualdades que viven las mujeres no me parece suficiente pedir la igualdad o paridad entre hombres y mujeres; defiendo una posición más radical. Pues después de varios siglos dominados por un poder masculino cuya estrategia básica era de polarizar lo máximo posible la sociedad, aumentar las diferencias y desigualdades, estamos entrando en un mundo posclásico, posmasculino, en el cual la meta más importante es combinar igualdad y diversidad. El elemento más importante de la nueva etapa de los movimientos de mujeres tiene como meta central reintegrar, reunificar lo que ha sido separado, jerarquizado, definido en términos de superioridad e inferioridad por las sociedades masculinas. Como las mujeres fueron víctimas de esta visión de los individuos y de la sociedad, son ahora ellas quienes deben tener y tienen el papel central en esta recomposición de la sociedad. Las primeras generaciones feministas, especialmente en Inglaterra, han luchado contra la desigualdad y han conseguido en muchos terrenos una igualdad de derechos real entre hombres y mujeres. Pero esta igualdad general basta. Son las mujeres las más capaces de transformar las sociedades dominadas por los hombres en sociedades que den la prioridad a la reintegración y a la igualdad de todos los componentes de la vida humana, lo que significa que las políticas sociales y educacionales deben ser inspiradas por mujeres. Más ampliamente creo en la necesidad de entrar y vivir en una sociedad de mujeres. 
El segundo tema es el más importante de todos, en particular porque después de un siglo de revoluciones y contrarrevoluciones la palabra democracia ha perdido cualquier tipo de sentido. El concepto de soberanía popular es demasiado monárquico y el filósofo político Claude Lefort con mucha razón ha escrito que lo importante no es saber quién se siente en el trono, monárquico o republicano, lo importante es que no haya ni trono ni soberano.

La única respuesta que me parece sólida y clara es que todos los ciudadanos tengan derechos fundamentales, políticos, sociales y culturales, derechos que por su mismo universalismo tienen una autoridad por encima de las leyes y decisiones del poder ejecutivo. Muchos países han decidido grabar estos derechos fundamentales en el preámbulo de su constitución. En el caso francés por supuesto, es la declaración de los Derechos de los Hombres y de los Ciudadanos de 1789; en los Estados Unidos es la Declaración de Independencia que constituye tal preámbulo. Los tribunales o cortes constitucionales son encargados de controlar la compatibilidad de todas las leyes con los principios fundamentales inscritos en la constitución.

En términos aún más claros y breves, la democracia es el reconocimiento por las instituciones y autoridades de un país de la legitimidad superior de los derechos universales, comparados con las mismas leyes y todas las decisiones públicas, legislativas, ejecutivas o del sistema judiciario. Los derechos de los ciudadanos tienen un nivel de legitimidad superior a cualquier decisión pública o privada.

Hoy en día escuchamos en todas partes del mundo voces humanas a menudo en los distritos más pobres: somos humillados; respeten por fin nuestra dignidad; trátennos como a cualquier ser humano, con los mismos derechos.

Muchos especialistas han definido la democracia por sus instituciones. La definición más breve y tal vez más conocida es una poliarquía electiva, creada por Robert Dahl en los Estados Unidos. Estos intentos, en realidad, siempre han fracasado. Basta recordar que Hitler fue elegido Reichskanzler de manera conforme al proceso constitucional.

El principio básico de la democracia es que cada ser humano tiene los mismos derechos individuales y colectivos que todos los demás sin tomar en cuenta su riqueza, su poder, sus capacidades intelectuales, su origen cultural, su género. Existe un acuerdo para no reconocer como ciudadano a los menores de edad, pero esta ley es cada vez más y más discutida. Existe una tendencia fuerte para reconocer la responsabilidad penal como los derechos de todos tipos a partir de una edad que va bajando constantemente y debe seguir bajando.

Aceptamos en general que las víctimas de enfermedades mentales no tengan los mismos derechos que los demás, pero existen muchos casos conocidos de enfermos mentales capaces de hablar de manera racional, de imaginar y realizar obras culturales y es un deber de cada sociedad el de limitar las consecuencias legales de lo que todavía Ilamamos de manera vaga enfermedad mental. 
Todas estas observaciones, por breves que sean, construyen una imagen clara de lo que debemos reconocer, individual y socialmente, como conductas destructoras de los derechos universales y contradictorias con los principios generales de Igualdad, Libertad y Fraternidad. Las leyes como los programas de educación o la política fiscal deben ser conformes a la inspiración general de los derechos universales de todos los seres humanos.

He dedicado una conferencia a la construcción estable y sólida de la relación de los chilenos con su pasado reciente y otra conferencia a la relación de los chilenos con su futuro próximo. Tal definición de las relaciones de un grupo humano con su pasado y su futuro, con su ayer y con su mañana, es una manera sólida de integrar un gran número de proyectos pasados -obviamente no todos- dentro de los proyectos de construcción de un porvenir que sea más justo, más libre y más solidario de lo que fue cualquier período de la historia nacional. 
